\title{
SALESMANSHIP BEHAVIOURAL PHYSIOGNOMIES AND BUSINESS PERFORMANCE OF BOVAS COMPANY LIMITED SOUTHWEST NIGERIA
}

\author{
Oyeniyi Aderonke Agnes \\ Osun State University, Okuku Campus, Osun State, Nigeria \\ agnes.oyeniyi@uniosun.edu.ng \\ Akanbi Bosede Esther \\ Osun State University, Okuku Campus, Osun State, Nigeria \\ bosede.akanbi@uniosun.edu.ng \\ Babatunde Bayode Olusanya \\ Osun State University, Okuku Campus, Osun State, Nigeria \\ bayode.babatunde@uniosun.edu.ng
}

\begin{abstract}
The paper objective is to investigate salesmanship behavioral physiognomies and performance of Bovas Company. The instrument used to collect data is a structured questionnaire, and the sample size for the study was 120. The research methodology adopted a descriptive research design to examine the impact of salesmanship behavioral characteristics and business performance. A purposive is appropriate since the population is not significant. Purposive sampling technique was employed to select and sample the opinion of the 120 respondents in the different Bovas filling stations selected for the study. Data were obtained from the field survey and was later analyzed using SPSS 20.0 (Statistical Package for Social Sciences). The results revealed a significant relationship between salesmanship skills and SMEs business performance $\left[r(117)=6.54^{* *}, p<.01\right]$. The hypothesis revealed a significant positive relationship between financial record keeping and business performance $[r(198)=08, p>0.5]$. Hypothesis three was supported by the result of the study. The study, therefore, concluded that salesman's characteristics such as integrity, trust and confidence are significant to business performance.
\end{abstract}

Keywords: Salesmanship, behavioral, performance, physiognomies, business performance.

\section{INTRODUCTION}

The business world is highly competitive; business owner employs diverse techniques to keep abreast of competition and to take advantage of the niche in the market. Most businesses in the $21^{\text {st }}$ century are falling apart, not because of lack of feasibility study and business plan but poor human resource 
capability. Bholanath and Girish (2011) defined Sale as the pinnacle activity involved in selling products or services in return for money or other compensation, it is further stated that it is an act of completion of commercial activity. Salesmanship is known widely for persuasion of customers, winning buyers' confidence, providing information among others.

UI Zia and Akram (2016) affirmed that companies are totally based on customer retention because customers are the critical factors of companies' success and without them, most companies will go out of business. It is, therefore, no doubt that salesperson is the link between the company and the customer or consumer. They are saddled with the responsibility of delivering information about the product and in some cases, selling may involve personal contact; this may occur through face-to-face meetings or via a telephone conversation. However, newer technologies allow communication to take place over the internet, including video conferencing, text messaging or online chat.

Because of the above assertion, who then is a salesperson? A sale person is a person who serves as intermediary or link between producer and consumer to deliver the goods or services produced by the organization in exchange for consideration in cash from the consumers with commission or salary attached on a weekly or monthly basis. As competition deepens, many organizations realize the need to retain its customer, which influences their sales and productivity. This can only be achieved through personal selling by the company salesperson. Popescu et al. (2018) explained that personal selling is known to be a powerful means by which an organisation obtains desired response from its customers and prospects. Ability to retain a customer is mostly dependent on salesmanship behaviour. Wiley \& Carolyn (2005) asserted that salesman personality is such that can perform his/her duties with the right personal characteristics, the right mind capabilities for selling.

It is observed that the management and operations of Medium scale business are confronted with some challenges which constitute the limitations hindering their growth in Nigeria. Medium business can be started with very minimal capital and without any formality. Many medium companies are operated as a family business and can be combined with regular employment. Some of the problems include a lack of huge capital to expand or take advantage of business opportunities. This also affects the remuneration of the salesmen who may not be well motivated to perform optimally.

Furthermore, lack of managerial skill affects the smooth and successful operation of medium businesses. Lack of planning skill by the medium business often resulted in business failure. Also, Poor decision making, and improper accounting constitute the problem confronted by medium companies, among other things. All these have implications on the performance of salesmen. The focus of the research is to investigate salesmanship behaviour characteristics and business performance. 
Quite a lot of studies have been carried out on Salesmanship across countries, including Nigeria. (Verbeke 1994; Magandini and Ngwenya, 2015; Bunea, 2019; Does, 2015), these studies have been useful in one way or the other for businessmen, private and public organisations to understand the psychology of salesmen and how to convert such to enhance employee's performance on the job. However, they have not been able to examine salesmanship behavioural characteristics and business performance on independent oil marketers like Bovas Nigeria limited. This suggests the reason to fill the existing study gap. It is on this note that the study seeks to examine the relationship between Salesmanship behavioural characterises and business.

\section{LITERATURE REVIEW}

\subsection{Salesmen Personality}

Organizations do not exist in a vacuum; they are established to meet the need of society to make a profit. Profit-making which is usually the target for setting up businesses cannot be achieved without employing people with the right attitudes, this is corroborated by Agodi et al. (2017) that in identifying, anticipating and satisfying customers' needs and wants effectively marketers must hire proactive salesmen. This suffices that customers can only be motivated to patronize business when salesmen possess the right personal attitude, which can arouse the interest of buyers. According to Agodi et al. (2017) personal selling is a presentation by the firm's salesmen for the purpose of matching, sales and building customer relationship.

It is seen to be an offshoot of sales performance. This is different from other means of promoting business through means as such bulletins, handbills and other forms of advertisement since it involves face to face negotiation and interactions which strengthens relationships. Convincing words from salesmen go a long way to stimulate customer's interest in buying. Words of mouth assist salesmen in adding value to their products or services merely because through dialogue advantages and disadvantages will be stressed and have known customers area of interest, convincingly buyers a times fall in to buy firms products. Customer relationship management is very vital in the success and sustainability of business (Corboș et al., 2019); hence the need to have front line salesmen who will satisfy customers to assist management achieve organizational goal.

UI Zia and Akram (2016) posited that ethical behavior of salesmen is fundamental in creating customer satisfaction simply because salesmen are presenting their organization's image in their behavior and interactions with customers. This informs that as the front-line staff, the first impression put up by them lasts longer. Their attitudes can make or limit the growth of an organization - UI Zia and Akram (2016) quoting stated that salesman ethical behavior has a significant impact on the customer's relationship 
and commitment. When a salesman has the right attitude, it will strengthen the relationship between customers and the organization which will, in turn, assist in enhancing the performance of the salesman. The honest actions of a sales representative can increase a customer's level of trust in the organization, which can facilitate frequent patronage. This is common, especially in the petrochemical industry, where buyers are always after accurate meter reading when buying petrol and other spirits. It makes some motorist stick to a petrol station and other branches due to their honesty and fair play to customers.

Petrochemical business is acknowledged to be very competitive, especially in Nigeria, where there are many independent marketers. The approach of salesmen at the stations go a long way in retaining some of the customers; hence, there is no way one can rule out putting men of integrity and ethical behavior at the petrol pumps, most of the time customers are increasingly impatient, and with more than one dispensing petrol pump, they look for the opportunity to get in front of a potential buyer who is already on the queue. This is most often an almost insurmountable challenge for the sales attendants.

The display of personal selling is a promotional method which assists a salesperson uses his skills and techniques for building a personal relationship with another person who is involved in deciding on purchasing. This suggests that a good and competent salesman must possess some attributes which will enhance his or her performance on the job.

\subsection{Attributes of A Salesman}

The personal attributes of salesmen cannot be farfetched; thus, they include:

$\checkmark$ Persuasive skill:

It is a common saying that customers are always right. The decision whether to buy or not, or whether to continue patronage with a firm lies with the customer. Bholanath and Girish (2011) opined that modern Salesmanship does not rely on pressure tactics or compulsion to clinch a sale; instead, the customer is led to favorable buying decision through careful and imaginative handling. It suffices that the salesman needs to create a favorable impression on the prospective buyer's mind by presenting the benefits associated with the product or service which the buyer stands to gain. This is corroborated by Magandini and Ngwenya (2015) who stated that sales personality is related to one's capability to perform the job that he or she has the right personal uniqueness and the right mind capabilities for selling, which means the persuasive attribute is a vital salesperson who wants to excel.

$\checkmark$ Building confidence in Buyers:

An educated and well-informed salesman will not only build up his own confidence on the job but instead be confident enough to persuade and educate buyers about the service or products including 
the values that are desirable with special features inherent in the product and their utility which will satisfy the customer's needs and aspirations. Supporting this assertion, Najum ul Zia et al. (2016) stated that if a salesperson gives right information or data, then the customer will feel more fulfilled by the service and the trust and fulfillment will be trailed by listening in on other's conversations suggestions.

\section{$\checkmark$ Information provider:}

Information is power, and power is the capacity to do something or act in a particular way. A salesman is supposed to be an information provider that will influence in a way the behavior of a buyer. Salesmanship, according to Bholanath et al. (2011) covers a wide range of activities and constitutes an integral part of management. Its wide range of activities, of course, depends on a considerable extent upon the line he is selling, and the channels of distributions adopted. The working knowledge of the salesman will enhance his ability to provide information about the firm, historical background of his company, detailed understanding of and working relationships with each of the departments and of course thorough knowledge of the product or service to be sold and how to better sell it. Feedback on customers is given to the company by a salesman who connects the customer and the firm together. Through the information supplied, attention will be given to observations and comments from customers to retain them.

\section{$\checkmark$ Empathy:}

A good salesman should know how to feel for customers and put himself in the shoes of his customers; this helps removing sentiment but instead stresses objectivity by getting inside a prospective customer's skin not only know to sell a product or service. Empathy is a great way to anticipate a customer's wants.

\section{$\checkmark$ Sales performance}

In the field of strategic management, sales performance is a widely discussed issue, but not easy to handle. Some scholars directly link the sales performance to the profit level, some use productivity (Porter, 1985; Bunea, 2019) or sales volume to define the meaning of sales performance. However, to compare the performance of sales, we can only use the subjective self -assessment of the salespeople such as empathy, assertiveness, ambitiousness, alertness and enthusiasm. A survey conducted by Gitomer (2001) found that the following characteristics if mastered, will boast sales performance of salesmen; yielding belief in the company, the product, and yourself, creativity to differentiate yourself from the competition, sense of humor that builds deep rapport, ability to promote yourself, ability to maintain price integrity, reliability, dependability, passion and desire to excel and be the best. 


\section{RESEARCH METHODOLOGY}

The study makes use of survey design to examine the salesmanship behavioral physiognomies and business performance in Bovas Nigeria Ltd. The population of the study comprises of the entire workers of Bovas Filling Stations in each of the state capital cities in the south-west region in Nigeria which includes Lagos, Ogun, Oyo, Osun, Ekiti and Ondo state. According to the managers of the stations interviewed, it was revealed the numbers of the staff in each of the filling stations were not equal but depending on the size and location not less than ten staff in each of Bovas stations. This led to choosing ten teams including station managers in each of the stations selected for the study, the total population of staff in these filling stations was 132 .

Purposive sampling technique was used to select the respondents in the study area. This approach was used to fulfill the specific objective and get information from the targeted respondents. 10 respondents were purposively selected in each of the filling stations. i.e. 20 respondents were selected each from the Bovas filling stations in Lagos, Ogun, Oyo, Osun, Ekiti and Ondo state. Also, all the total 12 managers were involved in the study. Therefore, the sample size was 132. The instrument used was the questionnaire. Questionnaires were administered with the assistance of the managers in the filling station selected for the study. All the 132 copies of Questionnaire administered to the respondents. However, out of 132 copies of questionnaire distributed, 117 were correctly filled and returned. The response rate was $87 \%$. Research data were analyzed through the Statistical Package for Social sciences (SPSS).

\subsection{Objectives of The Study}

The main objective of the study is to examine the relationship between salesmanship behavioral characteristics and business performance. Other specific objectives are to:

i. ascertains the influence of Salesmanship on business performance of the selected company.

ii. examine the influence of Salesmanship on business performance of selected company

iii. determine the level of relationship financial record keeping on business performance of the selected company.

\subsection{Hypotheses}

H01: Salesmanship behavioral characteristics do not have any significant relationship with business performance.

$\mathrm{Ho}_{2}$ : There is no significant influence between salesmanship skills and business performance

$\mathrm{Ho}_{3}$ : Financial record-keeping has no significant relationship in SME's performance. 


\section{RESULTS AND DISCUSSIONS}

\subsection{Results}

H01: Salesmanship behavioral characteristics do not have any significant relationship with business performance.

TABLE 1. DEMOGRAPHICS OF THE RESPONDENTS

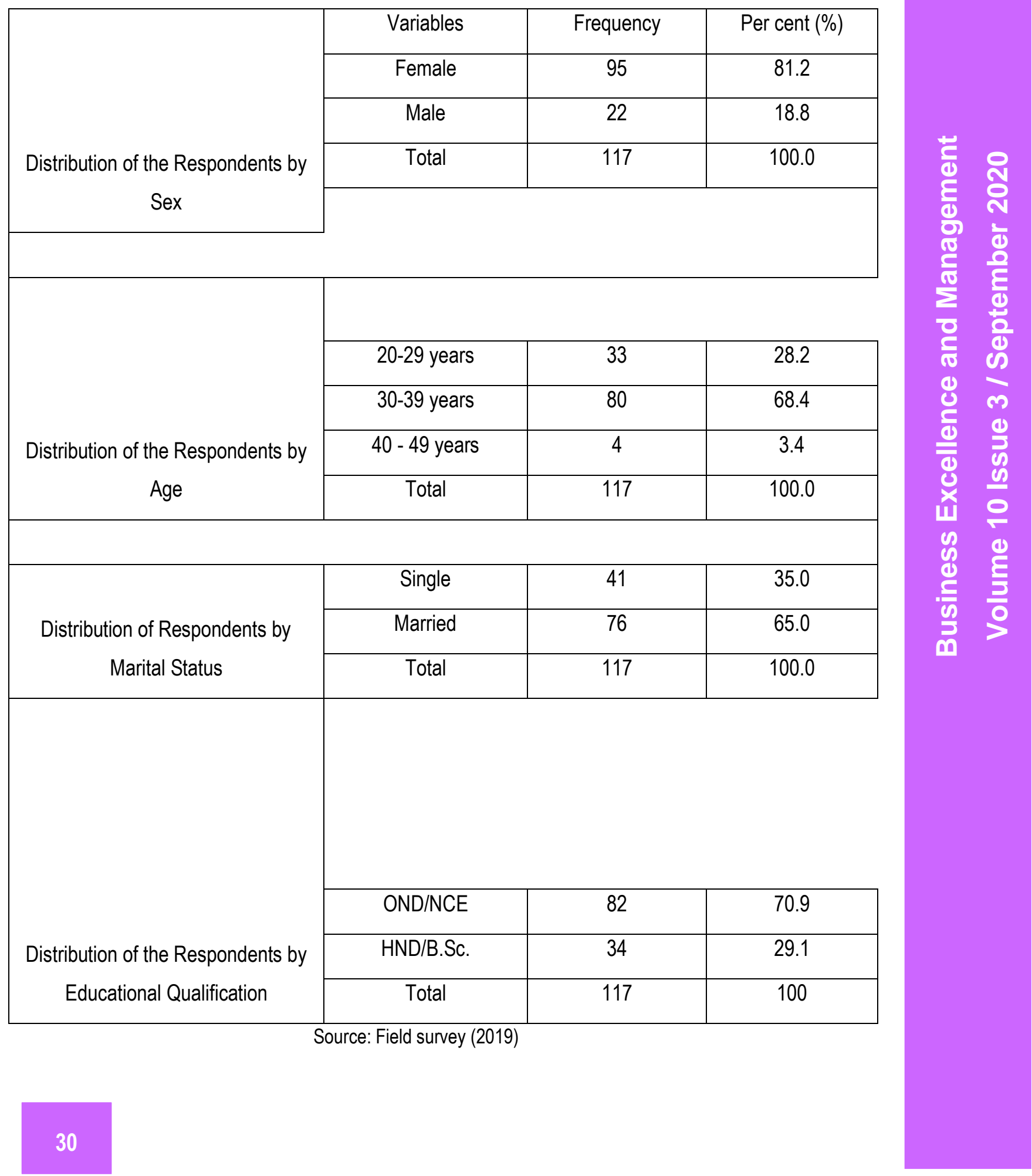


Table 1 shows the summary of the discussion of the respondent's by gender, the result revealed that as of the respondent representing $81.2 \%$ were females while 22 of the respondents representing $18.8 \%$ were male. Also, it revealed the frequency distribution of the respondents' age $33(23.6 \%)$ respondents are within the ages of 20 and 29 years, $80(57.1 \%)$ are within the ages of 30 to 39 years, $4(2.9 \%)$ are within the ages of 40 and 49 years old. Furthermore, it shows the marital status of the respondents with their frequencies. 41 of the respondents were single representing $35.0 \%$, and the married respondent was 76 frequencies $(65.0 \%)$. Conclusively the table also reveals that $82(58.6 \%)$ of the respondents have OND/NCE degree as their highest educational qualification, 31 (25.5\%) have HND/B.Sc. degree as their highest degree while $34(29.1 \%)$ as their most upper education.

TABLE 2. YEARS IN SERVICE

\begin{tabular}{|l|l|l|l|}
\hline$s / n$ & Variables & Frequency & Percentage \\
\hline 1. & $1-5$ years & 49 & 41.9 \\
\hline 2. & $6-10$ years & 68 & 58.1 \\
\hline & Total & 117 & 100.0 \\
\hline
\end{tabular}

Source: Field survey (2019)

Table 2 reveals $49(41.9 \%)$ respondents have been in service for a period of 1 - 5 years' and $68(58.1 \%)$ have been in service for a period of 6 - 10 years' work experience. This implies that all the respondents have spent a minimum of one year in service; therefore, their responses can be trusted. It also suggests that they might have gained experience and be more exposed to customers' psychology and how to relate to them. This supports Yusuf (2010) findings that when salesperson conduct is seen as moral, the organization is additionally regarded as virtuous. Also, the salesperson with high ethics could set up a good organization with the consumer, consequently getting customer loyalty and trust.

Ho2: There is no significant influence between salesmanship skills and business performance.

TABLE 3. A SUMMARY TABLE OF PEARSON, R CORRELATION SHOWING THE SIGNIFICANT INFLUENCE ON SALESMANSHIP SKILLS AND SMES BUSINESS PERFORMANCE

\begin{tabular}{|c|c|c|c|c|c|c|}
\hline Variables & $\mathrm{N}$ & $x$ & SD & Df & $R$ & $P$ \\
\hline Salesmanship skills & 117 & 31.26 & 11.04 & & & \\
\hline $\begin{array}{l}\text { SMEs business } \\
\text { performance }\end{array}$ & 117 & 70.47 & 28.54 & 117 & $6.54^{* *}$ & $<.01$ \\
\hline
\end{tabular}

Source: Author's Fieldwork, (2019.) 
The result in table 5 revealed that there was a significant influence on salesmanship skills and SMEs business performance $\left[r(117)=6.54^{\star *}, p<.01\right]$. Therefore, hypothesis three was fully supported by the result of the study. This informs that one of the salesmanship skills include words of mouth which is dominant in relating to customers. It assists salesmen to add value to their products or services merely because through dialogue, the importance of a product or service will be stressed, and the customer's area of interest will be known.

$\mathrm{H}_{3}$ : Financial record-keeping has no significant relationship in business performance.

This stated that financial record keeping has no significant relationship with SME's performance.

TABLE 4: SUMMARY TABLE OF PEARSON, R CORRELATION SHOWING THE RELATIONSHIP BETWEEN FINANCIAL RECORD KEEPING AND SME'S PERFORMANCE

\begin{tabular}{|c|c|c|c|c|c|c|}
\hline Variables & $\mathrm{N}$ & $\bar{X}$ & SD & Df & $\mathrm{T}$ & $P$ \\
\hline $\begin{array}{l}\text { Financial } \\
\text { record- } \\
\text { keeping }\end{array}$ & 117 & 28.14 & 8.95 & \multirow[t]{2}{*}{117} & \multirow[t]{2}{*}{5.08} & \multirow[t]{2}{*}{$>.05$} \\
\hline $\begin{array}{l}\text { SME's } \\
\text { performance }\end{array}$ & 117 & 70.47 & 28.54 & & & \\
\hline
\end{tabular}

Source: Author's Fieldwork (2019).

The result in table 5 above showed that there there was a significantly positive relationship between financial record keeping and SMEs performance $[r(198)=-.08, p>0.5]$.

\subsection{Discussions}

Majority of the respondents were females with (81.2\%), thus implying that oil business is a femaledominated enterprise maybe because of the nature of the shifting of the job. 80 of the respondents, respectively $68.4 \%$, were in their youthful, active years and married, while males represented $18.8 \%$ of the respondents. From the information gathered, all the respondents have formal education with superior studies. This depicts that's as salesman education is germane due to the sensitive nature of the job ranging from record-keeping on sales, meter reading and other related responsibility. This is in support of Magandini and Ngwenya (2015); they confirmed that sales personality is similar to one's ability to perform and is also explained as the quality and quantity of sales closed at a particular time frame.

Also, most of the salesmen are experienced workers who have spent more than one year in the enterprise. The more the salesmen get used to processes involved in the petrol chemical business, the 
higher will be the level of trust and good human relation with colleagues and customers which will enhance higher profit and customer retention. This agrees with the findings of Bholanath and Girish (2011) that sale representative agent behaviors' may be considered opportunistic and inconsistent, which may inhibit trust-building. On the contrary, the entrepreneur participants seem to engage in acts that have been shown to inspire confidence and respect, which stimulate trust. This is also in agreement with the findings of UI Zia and Akram (2016) that a customer-oriented salesperson put additional exertion in understanding the customer's feelings to impact customer inclination constructively.

\section{CONCLUSIONS AND RECOMMENDATIONS}

This study examined salesmanship behavioral characteristics and business performance. Sales force would be the critical factor for business survival, especially in a highly competitive market. If firms want their profit to keep growing, they must rely on the salespeople to promote products launched to the customers. Therefore, the salespeople must make great effort to collect information and identify potential customers in other to attain the selling goals and obtain the necessary profit for the firm to survive. A significant relationship exists between salesmen personality traits and their sales performances.

The preceding analysis and results from this study demonstrated that salesmanship abilities in salespeople will influence business performance and also have a higher level of learning about the customer. Results from this study show that business performance prompts more grounded feeling regulation capacities in salespeople. From discoveries, it is recommended that salesperson must put additional exertion in understanding and directing the customer's feelings to impact customer inclination constructively. This will make the salesperson successful in sales transactions and enhance business performance

Based on the findings of this study, the following recommendations were made:

$>$ Sales managers should establish specific, short-term or immediate goals or sales targets that will challenge the salespeople, yet still viewed as achievable and realistic.

$>$ From discoveries, it is recommended that a salesperson must put additional exertion in understanding and directing the customer's feelings to impact customer inclination constructively. This will make the salesperson successful in sales transactions and enhance business performance.

$>$ Sales managers should reduce stressful and tense situations while lowering anxiety surrounding the selling process or sales process of the salespeople. Salesperson's ambitious 
potential for achieving sales target or quotas should also be improved or made better through guided practice, mentoring and role modelling.

Employers should use personality traits as criteria in selecting more effective salespeople and in designing job characteristics that optimally fit the profile of proactive employees. Additionally, training interventions may be adapted to the differential needs of individuals who score high versus low on personality traits.

\section{REFERENCES}

Agodi, J.E., Ahaiwe, E.O., Awah, A.E. (2017). Salesmanship personality trait and its effect on sales performance: Study of fast-moving consumer goods (FMCG) in Abia State, Nigeria. Journal of Economics and sustainable development. 8(24): 81 - 88.

Bholanath, D. and Girish, C. (2011). Salesmanship. Himalaya Publishing House. Mumbai, India.

Bunea, O. I. (2019, May). Repositioning sales as an influence on innovation and a source of sustainable competitive advantage. In Proceedings of the International Conference on Business Excellence (Vol. 13, No. 1, pp. 492-504). Sciendo.

Bunea, O. I. (2019). THE STRATEGIC ROLE OF THE SALES TEAM IN INCREASING THE COMPETITIVENESS OF THE FIRM. Calitatea, 20(S2), 130-135.

Corboş, R. A., Popescu, R. I., \& Bunea, O. I. (2019). The influence of the sales management style on the company's competitiveness. Calitatea, 20(S2), 197-201.

Gitomer, J. (2001). Specific characteristics are what make top salespeople tops. American City Business Journal.

Does, J.F. (2015). Exploring the salesmanship/Entrepreneurship dynamics. A PhD Thesis submitted in partial fulfillment of the requirements of the University of the University of West of England, Bristol. 1- 109

Magandini \& Nywenya (2015). The Effects of salesman personality on sales performance of internet service provider in the Telecommunication Industry: Zimbabwean Perspective. British Journal of marketing studies. 3 (1): 11 - 22.

Popescu, R. I., Corboş, R. A., \& Bunea, O. I. (2018). Selling cultural organizations-a case study on client's perception of the cultural activity of the Calea Victoriei Foundation. Administratie si Management Public, (31), 81-96.

Porter, M.E (1985). Competitive Advantage. Ist Edition, Free press, New York. 15 - 25

UI Zia, N., \& Akram, M. W. (2016). Impact of Salesman Behavior on Customer Satisfaction: An Emprical Study of Dairy Retail Handlers. Kuwait Chapter of the Arabian Journal of Business and Management Review, 5(8), 20.

Verbeke, W. (1994). Personality characteristics that predict effective performance of sales people. Scandinavian Journal of Management, 10(1), 49-57. 
Oyeniyi A.A., Akanbi B.E., Babatunde B.O.

SALESMANSHIP BEHAVIOURAL PHYSIOGNOMIES AND BUSINESS PERFORMANCE OF BOVAS COMPANY

LIMITED SOUTHWEST NIGERIA

Wiley, C. and Carolyn, E. (2005). What motivate employees according to over 40 years of motivation surveys. International Journal of Manpower. 18 (1): 263 - 281.

Yusuf, J. B. (2010). Ethical implications of sales promotion in Ghana: Islamic perspective. Journal of Islamic Marketing, 1(3), 220. 